ARTIGO ORIGINAL

\title{
Variabilidade das densidades básica e energética e estoque de carbono na madeira no fuste de clones de Eucalyptus
}

\author{
Variability of basic and energy densities and wood carbon stock in Eucalyptus \\ clones' trunks
}

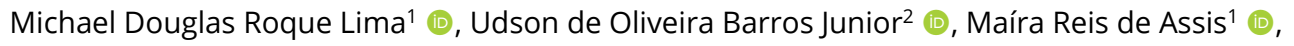 \\ Isabel Cristina Nogueira Alves de Melo ${ }^{1}$ (D), Izabel Cristina Rodrigues de Figueiredo ${ }^{3}$ (D), \\ Thiago de Paula Protásio ${ }^{2}$ (D), Paulo Fernando Trugilho ${ }^{1}$ (1) \\ ${ }^{1}$ Universidade Federal de Lavras - UFLA, Lavras, MG, Brasil \\ ${ }^{2}$ Universidade Federal Rural da Amazônia - UFRA, Parauapebas, PA, Brasil \\ ${ }^{3}$ Grupo Plantar, Curvelo, MG, Brasil
}

\begin{abstract}
Como citar: Lima, M. D. R., Barros Junior, U. O., Assis, M. R., Melo, I. C. N. A., Figueiredo, I. C. R., Protásio, T. P., \& Trugilho, P. F. (2020). Variabilidade das densidades básica e energética e estoque de carbono na madeira no fuste de clones de Eucalyptus. Scientia Forestalis, 48(128), e3302. https://doi.org/10.18671/scifor.v48n128.04
\end{abstract}

\begin{abstract}
Resumo
Escassas são as publicações que avaliam as variações das propriedades do lenho, ao longo do fuste, de elevado número de clones de Eucalyptus. Dessa forma, o objetivo desta pesquisa foi avaliar a variação longitudinal das densidades básica e energética e estoque de carbono na madeira de clones do gênero Eucalyptus. Foram avaliados 39 clones de Eucalyptus spp., aos 81 meses de idade, dos quais foram amostradas 3 árvores por material genético, sendo retiradas amostras de madeira ao longo de 5 posições do fuste $(2 \%, 10 \%, 30 \%, 50 \%$ e $75 \%$ da altura comercial). O experimento foi desenvolvido em delineamento inteiramente casualizado (DIC), disposto em parcelas subdivididas. Há dependência entre clone e posição longitudinal para densidade básica, estoque de carbono na madeira e densidade energética. Foram encontrados quatro padrões de variação de densidade básica para os clones de Eucalyptus urophylla. Verificou-se forte correlação da densidade básica com estoque de carbono $(r=0,9893)$ e densidade energética da madeira $(r=0,9798)$. A densidade básica da madeira apresenta padrões de média e baixa variabilidade entre os materiais genéticos e posições longitudinais do fuste, respectivamente. Os clones 1001, 1009, 1025 e 1039 foram os mais indicados para fins bioenergéticos, pois apresentaram elevados valores de densidade básica, estoque de carbono e densidade energética da madeira.
\end{abstract}

Palavras-chave: Materiais genéticos; Classificação de clones; Densidade energética; Carvão vegetal.

\begin{abstract}
There are few publications evaluating wood variation properties along the stem of many Eucalyptus clones. Thus, the aim of this research was to evaluate the longitudinal variation of the basic density, wood carbon stock, and energy density of clones in the genus Eucalyptus. 39 Eucalyptus sp. clones were evaluated at 81 months of age; with 3 trees sampled according to genetic material, and samples from 5 longitudinal positions along the stem collected at 2\%, 10\%,30\%,50\%, and $75 \%$ of the commercial height. The characteristics evaluated in these positions were basic density; carbon stock and wood energy density. The experiment was conducted in a completely randomized design (CRD), arranged in split plot design. There is dependence between clone and longitudinal position for basic density, carbon stock, and energy density. Four variation patterns of basic density were found for the Eucalyptus urophylla clones. There was a strong correlation of the basic density with carbon stock ( $r=0.9893)$ and wood energy density
\end{abstract}

Fonte de financiamento: Coordenação de Aperfeiçoamento de Pessoal de Nível Superior (código de financiamento 001), Conselho Nacional de Desenvolvimento Científico e Tecnológico (processos n 141439/2014-9 e n 306793/2019-9), Fundação de Amparo a Pesquisa do Estado de Minas Gerais (processo PPM-00210-18) e Grupo Plantar.

Conflito de interesse: Nada a declarar.

Autor correspondente: lima_florestal@outlook.com

Recebido: 27 fevereiro 2019.

Aceito: 16 outubro 2019.

Editor: Paulo Henrique Müller Silva.

(c) (i) Este é um artigo publicado em acesso aberto (Open Access) sob a licença Creative Commons Attribution, que permite uso, distribuição e

c) reprodução em qualquer meio, sem restrições desde que o trabalho original seja corretamente citado. 
$(r=0.9798)$. Wood basic density presented patterns of medium and high variability between genetic materials and longitudinal positions along the stem, respectively. Clones 1001, 1009, 1025, and 1039 were the most suitable for bioenergy purposes due the high values of basic density, carbon stock, and wood energy density.

Keywords: Genetic materials; Clone classification; Energy density; Charcoal.

\section{INTRODUÇÃO}

As espécies do gênero Eucalyptus são reconhecidas pelo rápido crescimento, alta produtividade, ampla adaptabilidade ambiental e utilização da madeira, além da contribuição quanto à diminuição da pressão sobre os ecossistemas nativos (Wink et al., 2013). A madeira de eucalipto é empregada como matéria-prima no segmento de celulose e papel, serrarias, usinas de preservação, indústrias de painéis e chapas de madeira e produção bioenergética (Santos et al., 2012).

A definição do uso comercial da madeira é baseada, principalmente, na avaliação das propriedades do lenho. A densidade básica, grã, textura, dureza e cor são características bastante utilizadas na qualificação e classificação de madeiras (Mori et al., 2004). Destaca-se o uso da densidade básica na avaliação tecnológica da madeira (Rodrigues et al., 2008), principalmente pela relação com outras propriedades físicas, mecânicas e energéticas do xilema secundário (Dias et al., 2018) e pela facilidade de determinação em condição de laboratório e de campo (Batista et al., 2010).

A densidade básica pode variar de diversas formas, entre espécies botânicas, entre árvores da mesma espécie, entre indivíduos do mesmo clone e ao longo do fuste da mesma árvore (Couto et al., 2012). Barotto et al. (2017) encontraram valores de densidade básica distintos entre Eucalyptus grandis $\left(0,421 \mathrm{~g} \mathrm{~cm}^{-3}\right)$, Eucalyptus viminalis $\left(0,665 \mathrm{~g} \mathrm{~cm}^{-3}\right)$ e Eucalyptus globulus $\left(0,545 \mathrm{~g} \mathrm{~cm}^{-3}\right)$. Barotto et al. (2018) reportaram variação intraespecífica de densidade básica $\left(0,65 \mathrm{~g} \mathrm{~cm}^{-3}\right.$ e $\left.0,59 \mathrm{~g} \mathrm{~cm}^{-3}\right)$ em dois materiais genéticos de Eucalyptus globulus. Zanuncio et al. (2013) avaliaram materiais genéticos do gênero Eucalyptus e Corymbia e registraram relação inversamente proporcional da densidade básica com a umidade $(r=-0,944)$ e taxa de secagem $(r=-0,761)$. Assim, é possível inferir que: (i) árvores com elevada densidade básica apresentam menores taxas de secagem e (ii) que o entendimento da variação da densidade básica ao longo do fuste comercial de clones de Eucalyptus interfere principalmente no gerenciamento florestal.

A densidade básica está fortemente relacionada com a produção energética, quanto maior a densidade básica, maior será a quantidade de energia estocada por metro cúbico (Carneiro et al., 2014). Adicionalmente, o potencial energético da madeira pode ser dimensionado com dados de densidade básica e teor de carbono elementar do xilema secundário (Protásio et al., 2014). A capacidade de estoque de carbono está relacionada à absorção do carbono atmosférico $\left(\mathrm{CO}_{2}\right)$ promovido pelas árvores que, em seu processo natural de fotossíntese, fixa o carbono em sua estrutura interna, culminando com a produção de biomassa e liberando oxigênio para o meio (Litton et al., 2007; Trugilho et al., 2010; Silva et al., 2015).

No tocante aos reflorestamentos, a produção de biomassa é maximizada em função do aumento da taxa de crescimento dos indivíduos. Vale enfatizar que a quantificação do carbono estocado na biomassa, em reflorestamentos com Eucalyptus, corrobora o importante papel desse modelo produtivo no contexto da sustentabilidade do setor florestal (Luna et al., 2016).

Nesse sentido, a maior quantidade estocada de carbono proporcionará maior geração de energia limpa (Santos et al., 2012). Gatto et al. (2011) verificaram em seu estudo que 64,7\% do carbono estocado na parte aérea de árvores de Eucalyptus sp. se concentraram no caule. Entretanto, informações do estoque de carbono no sentido longitudinal da madeira de Eucalyptus são escassas na literatura. 
Portanto, o presente estudo buscou responder às seguintes questões científicas: (i) Como se dá a variação das densidades básica e energética e estoque de carbono da madeira no sentido base-topo em clones do gênero Eucalyptus? Além disso, como a densidade básica influencia o estoque de carbono e a densidade energética do lenho?

Com isso, o objetivo dessa pesquisa foi avaliar as variações da densidade básica, da densidade energética e do estoque de carbono da madeira no sentido base-topo em clones do gênero Eucalyptus, provenientes de plantios homogêneos.

\section{MATERIAL E MÉTODOS}

\section{Material biológico}

No presente estudo foram avaliados trinta e nove clones de Eucalyptus sp. provenientes de teste clonal $\left(18^{\circ} 45^{\prime} 06.44^{\prime \prime} \mathrm{S} ; 4^{\circ} 33^{\prime} 39.16^{\prime \prime} \mathrm{O}\right.$ e $690 \mathrm{~m}$ de altitude) da empresa Plantar, localizada no município de Curvelo, Minas Gerais (Figura 1). Segundo a Köppen e Geiger, Curvelo apresenta clima do tipo Aw. A precipitação média anual da região é de $1.221 \mathrm{~mm}$ e a temperatura média de $22,1^{\circ} \mathrm{C}$ (Climate-Data.Org, 2017).
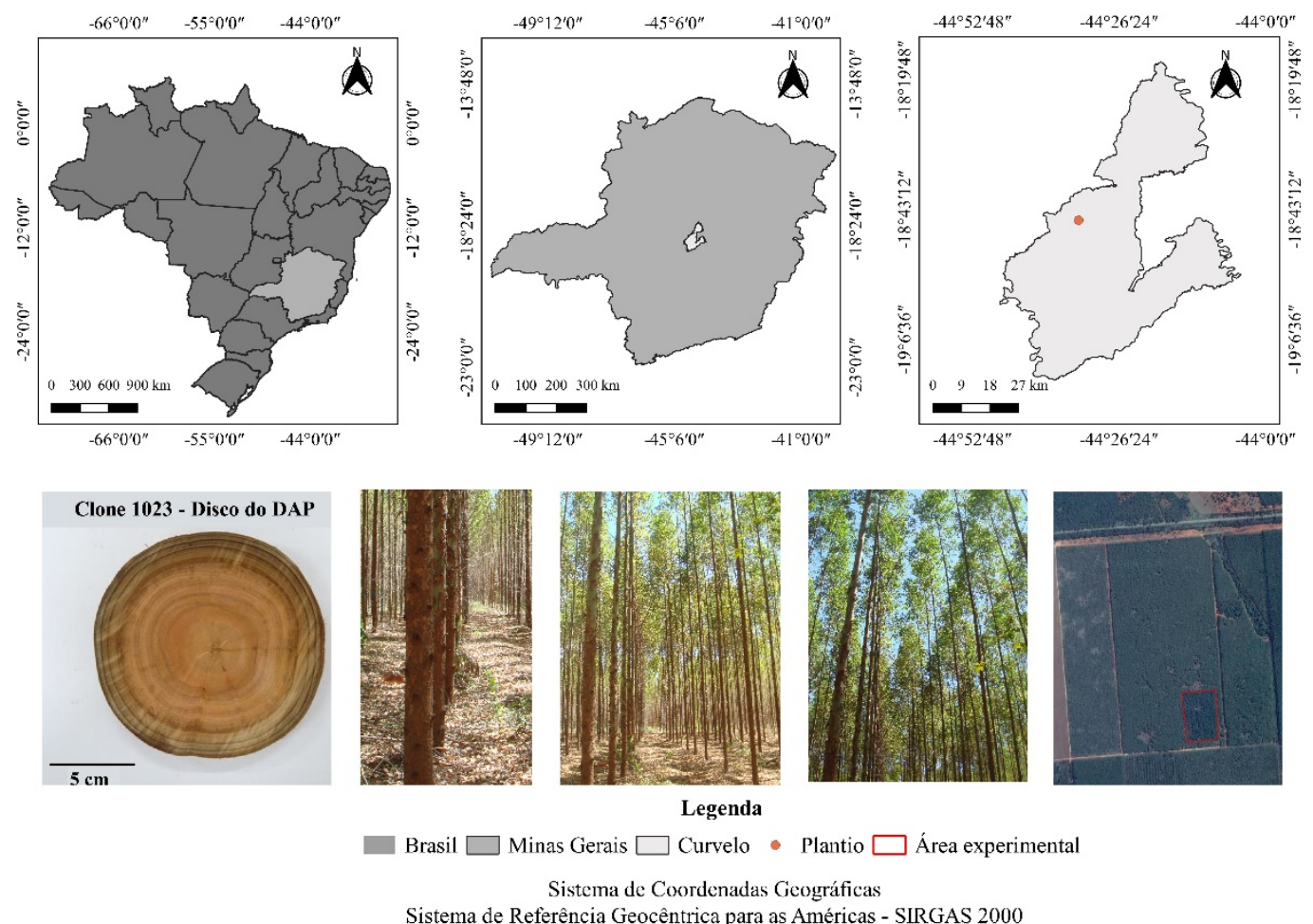

Figura 1. Localização do teste clonal de Eucalyptus avaliado no município de Curvelo, Minas Gerais, Brasil. Fonte: Protásio et al. (2019)

São discriminados na Tabela 1 os clones estudados com seus respectivos valores médios de altura total $(\mathrm{HT})$, altura comercial $(\mathrm{Hc})$ e diâmetro com casca medido a 1,30 $\mathrm{m}$ do solo (DAPcc). Os clones apresentavam oitenta e um meses de idade e o espaçamento de plantio

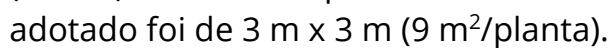


Tabela 1. Relação dos materiais genéticos de Eucalyptus avaliados aos 81 meses de idade em Curvelo, Minas Gerais, Brasil.

\begin{tabular}{|c|c|c|c|c|c|}
\hline $\mathbf{N}^{\circ}$ & Clone & Espécie/Híbrido & HT (m) & $\mathrm{HC}(\mathrm{m})$ & DAPcc (cm) \\
\hline 1 & 1001 & E. urophylla & 21,13 & 18,73 & 14,5 \\
\hline 2 & 1002 & Eucalyptus sp. & 25,43 & 23,23 & 15,9 \\
\hline 3 & 1003 & E. urophylla & 24,30 & 21,63 & 15,3 \\
\hline 4 & 1004 & E. urophylla $\times$ E. camaldulensis & 24,50 & 21,73 & 15,1 \\
\hline 5 & 1005 & E. urophylla & 23,43 & 21,03 & 15,8 \\
\hline 6 & 1006 & E. urophylla & 25,73 & 23,28 & 17,2 \\
\hline 7 & 1007 & E. urophylla & 25,37 & 23,03 & 16,6 \\
\hline 8 & 1008 & E. urophylla & 23,53 & 20,83 & 16,6 \\
\hline 9 & 1009 & E. urophylla & 23,93 & 21,47 & 15,5 \\
\hline 10 & 1010 & E. urophylla & 24,10 & 21,82 & 16,7 \\
\hline 11 & 1011 & E. urophylla & 22,57 & 19,47 & 14,9 \\
\hline 12 & 1012 & E. urophylla $\times$ E.grandis & 23,93 & 21,37 & 14,1 \\
\hline 13 & 1013 & E. urophylla $\times$ E. grandis & 22,43 & 20,03 & 15,4 \\
\hline 14 & 1014 & E. grandis & 22,50 & 19,82 & 14,3 \\
\hline 15 & 1015 & E. urophylla & 24,07 & 21,43 & 15,0 \\
\hline 16 & 1016 & Eucalyptus sp. & 24,50 & 21,38 & 15,4 \\
\hline 17 & 1017 & Eucalyptus sp. & 23,93 & 21,60 & 14,6 \\
\hline 18 & 1018 & Eucalyptus sp. & 24,90 & 22,27 & 16,8 \\
\hline 19 & 1019 & Eucalyptus sp. & 23,80 & 21,55 & 14,6 \\
\hline 20 & 1020 & Eucalyptus sp. & 21,80 & 19,35 & 15,5 \\
\hline 21 & 1021 & Eucalyptus sp. & 22,10 & 19,75 & 15,5 \\
\hline 22 & 1022 & E. urophylla $\times$ E.grandis & 23,52 & 20,60 & 14,2 \\
\hline 23 & 1023 & Híbrido de E. urophylla & 22,77 & 20,23 & 13,9 \\
\hline 24 & 1024 & Híbrido de E. urophylla & 22,73 & 20,40 & 14,7 \\
\hline 25 & 1025 & Híbrido de E. camaldulensis & 23,30 & 19,95 & 14,1 \\
\hline 26 & 1026 & E. urophylla $\times$ E.grandis & 22,80 & 20,13 & 16,2 \\
\hline 27 & 1027 & E. urophylla $\times$ E. grandis & 22,90 & 20,73 & 16,5 \\
\hline 28 & 1028 & E. pellita $\times$ E. grandis & 20,50 & 18,02 & 15,0 \\
\hline 29 & 1029 & E. urophylla $\times$ E. grandis & 23,07 & 20,33 & 15,4 \\
\hline 30 & 1030 & Eucalyptus sp. & 25,13 & 22,77 & 15,2 \\
\hline 31 & 1031 & Eucalyptus sp. & 26,12 & 23,67 & 17,1 \\
\hline 32 & 1032 & Eucalyptus sp. & 22,53 & 20,27 & 15,4 \\
\hline 33 & 1033 & Híbrido de E. urophylla & 25,47 & 22,72 & 15,5 \\
\hline 34 & 1034 & E. urophylla & 26,20 & 23,85 & 16,8 \\
\hline 35 & 1035 & E. urophylla & 24,17 & 22,25 & 15,8 \\
\hline 36 & 1036 & E. urophylla & 23,12 & 20,53 & 14,0 \\
\hline 37 & 1037 & Eucalyptus sp. & 25,10 & 21,65 & 19,6 \\
\hline 38 & 1038 & E. urophylla & 24,35 & 21,43 & 15,5 \\
\hline 39 & 1039 & Híbrido de E. grandis & 21,93 & 19,22 & 15,7 \\
\hline
\end{tabular}

HT e Hc = alturas total e comercial, DAPcc = Diâmetro com casca medido a 1,30 m do solo. Fonte: Protásio et al. (2017)

Foram amostradas de forma casual três árvores de diâmetro médio por material genético. Nas árvores, foram retirados discos de $2,5 \mathrm{~cm}$ de espessura, em cinco posições longitudinais, ou seja, 2\%, 10\%, 30\%, 50\% e 75\% da altura comercial da árvore, considerada até um diâmetro mínimo de 4,0 cm com casca, conforme recomendações de Downes et al. (1997). 


\section{Análises realizadas na madeira}

Os discos retirados das árvores foram seccionados em quatro cunhas passando pela medula. Duas menores cunhas opostas foram utilizadas na determinação da densidade básica da madeira, seguindo as recomendações da norma NBR 11941 da Associação Brasileira de Normas Técnicas (Associação Brasileira de Normas Técnicas, 2003). A densidade básica da árvore foi obtida, a partir da média aritmética, considerando os cinco pontos da amostragem longitudinal ao longo do tronco das árvores.

A densidade energética, quantidade de energia por unidade de volume de um material combustível, foi obtida pelo produto da densidade básica da madeira pelo poder calorífico inferior, conforme a Equação 1.

$\mathrm{DE}=\mathrm{DB} \times \mathrm{PCI}$

em que, DE é a densidade energética $\left(\mathrm{kcal} \mathrm{m}^{-3}\right)$; DB é a densidade básica da madeira $\left(\mathrm{kg} \mathrm{m}^{-3}\right)$; e PCl é o poder calorífico inferior médio por material genético $\left(\mathrm{kcal} \mathrm{kg}^{-1}\right)$.

O poder calorífico inferior foi estimado com base na Equação 2, desconsiderando-se o calor latente de vaporização do vapor d'água formado pela combustão do hidrogênio de constituição elementar.

$\mathrm{PCI}=\mathrm{PCS}-(600 \times 9 \mathrm{H} / 100)$

em que, $\mathrm{PCl}$ é o poder calorífico inferior $\left(\mathrm{kcal} \mathrm{kg}^{-1}\right)$; PCS é o poder calorífico superior ( $\mathrm{kcal} \mathrm{kg}^{-1}$ ) e $\mathrm{H}$ é o teor de hidrogênio (\% na base massa seca).

Para a quantificação do poder calorífico superior (PCS), utilizou-se um calorímetro digital da marca IKA C-200, conforme norma ABNT NBR 8633 (Associação Brasileira de Normas Técnicas, 1984). Os teores de carbono $(C)$ e hidrogênio $(H)$ levando em consideração à massa seca da madeira dos clones foram determinados por meio da análise elementar realizada em analisador universal da marca Elementar (modelo Vario Micro Cube), da mesma forma que utilizada por Leite et al. (2015).

O estoque de carbono na madeira por unidade de volume (ECM) foi calculado por posição longitudinal e por clone, em ambos os casos foi utilizada a Equação 3, conforme metodologia de Protásio et al. (2013).

$\mathrm{ECM}=\mathrm{DB} \times(\mathrm{C} / 100)$

em que, ECM é o estoque de carbono na madeira $\left(\mathrm{kg} \mathrm{m}^{-3}\right)$; DB é a densidade básica da posição longitudinal ou a média para o clone $\left(\mathrm{kg} \mathrm{m}^{-3}\right)$; e $\mathrm{C}$ o teor de carbono médio por material genético (\%).

\section{Delineamento experimental e análise estatística}

Foi utilizado o delineamento experimental inteiramente casualizado (DIC), disposto em parcelas subdivididas, sendo que o clone foi o efeito da parcela e a posição longitudinal de amostragem o efeito da subparcela. Foram consideradas 3 repetições (árvores) e 5 posições longitudinais para cada um dos trinta e nove clones.

Para as análises estatísticas foi utilizado o software $R \circledast$ versão 3.4.3 (R Core Team, 2017) e os pacotes car (Fox; Weisberg, 2011) e ExpDes (Ferreira et al., 2018). Preliminarmente, foram aplicados os testes de Levene $(p \leq 0,05)$ e Kolmogorov-Smirnov $(p \leq 0,05)$ para verificar a homogeneidade de variância e a normalidade dos dados. Além disso, foi observada a 
dispersão gráfica dos resíduos do modelo estatístico utilizado. Os dados foram submetidos à análise de variância (ANAVA) e quando houve efeito da interação entre os fatores este foi analisado. Para análise do efeito de posição longitudinal de amostragem dentro de cada clone foram ajustados modelos de regressão linear simples. O teste de Scott-Knott $(p \leq 0,05)$ foi utilizado para verificação da similaridade dos clones dentro de cada posição longitudinal.

\section{RESULTADOS E DISCUSSÃO}

Os dados de densidade básica da madeira seguiram distribuição normal ( $p$-valor = 0,1621) pelo teste de Kolmogorov-Smirnov ao nível de 5\% de significância (Figura 2). Considerando todas as posições longitudinais, a densidade básica apresentou média aritmética de $0,524 \mathrm{~g} \mathrm{~cm}^{-3}$, portanto, as madeiras dos clones de Eucalyptus foram classificadas como de média densidade, segundo IAWA (Wheeler et al., 1989).

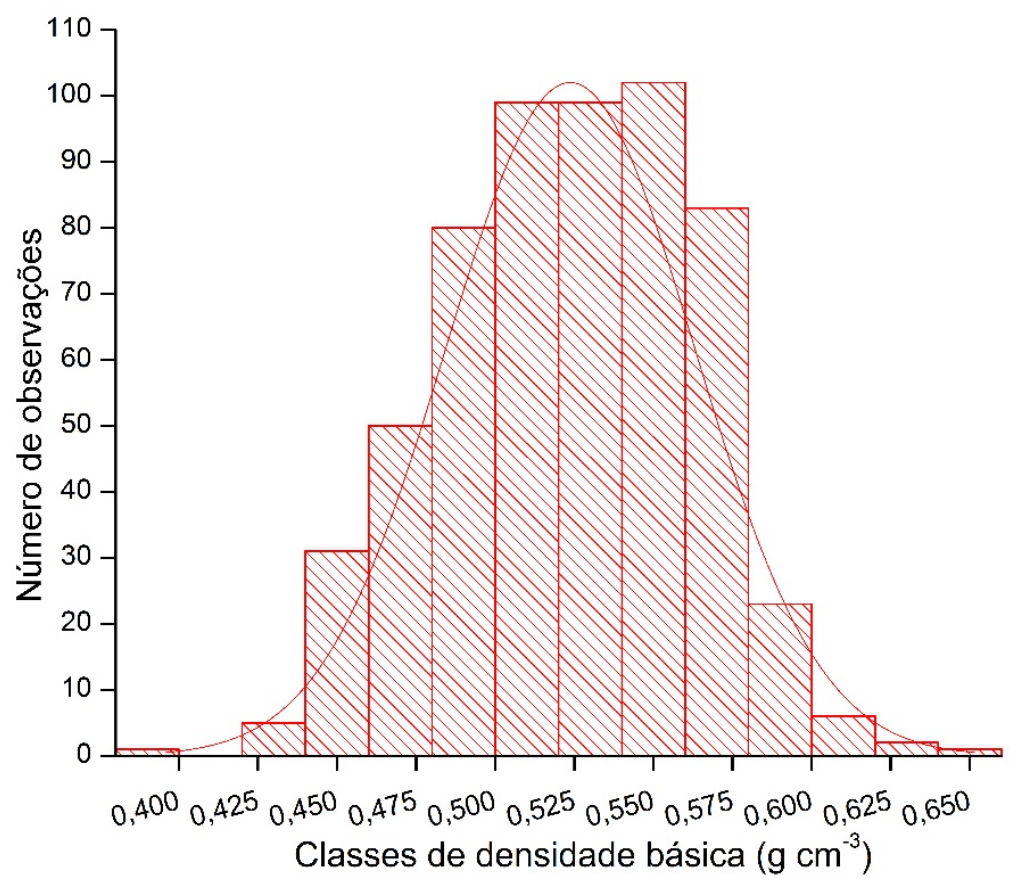

Figura 2. Curva de distribuição da densidade básica da madeira considerando todas as posições longitudinais de amostragem no tronco das árvores.

O teste $\mathrm{F}(p \leq 0,05)$ mostrou efeito significativo da interação clone $\mathrm{x}$ posição longitudinal do fuste para a densidade básica, estoque de carbono e densidade energética da madeira (Tabela 2), indicando a existência de dependência entre estes fatores.

A densidade básica dos clones avaliados por posição longitudinal pode ser visualizada na Figura 3. Foi observada variação de $0,453 \mathrm{~g} \mathrm{~cm}^{-3}$ (1008) a $0,592 \mathrm{~g} \mathrm{~cm}^{-3}$ (1039) na posição $2 \%$; $0,428 \mathrm{~g} \mathrm{~cm}^{-3}$ (1008) a $0,573 \mathrm{~g} \mathrm{~cm}^{-3}$ (1001) na posição $10 \%$; $0,448 \mathrm{~g} \mathrm{~cm}^{-3}$ (1034) a $0,620 \mathrm{~g} \mathrm{~cm}^{-3}$ (1001) na posição $30 \%$; $0,448 \mathrm{~g} \mathrm{~cm}^{-3}$ (1008) a $0,591 \mathrm{~g} \mathrm{~cm}^{-3}$ (1017) na posição $50 \%$ e de $0,479 \mathrm{~g}$ $\mathrm{cm}^{-3}$ (clone 1026) a $0,588 \mathrm{~g} \mathrm{~cm}^{-3}$ (clone 1009) na posição $75 \%$. Em ordem, a maior e menor variação foi verificada nas posições de $30 \%\left(0,172 \mathrm{~g} \mathrm{~cm}^{-3}\right)$ e $75 \%\left(0,109 \mathrm{~g} \mathrm{~cm}^{-3}\right)$ da altura comercial. Os valores médios de densidade básica da madeira foram de $0,522 \mathrm{~g} \mathrm{~cm}^{-3}, 0,507 \mathrm{~g}$ $\mathrm{cm}^{-3}, 0,524 \mathrm{~g} \mathrm{~cm}^{-3}, 0,532 \mathrm{~g} \mathrm{~cm}^{-3} \mathrm{e} 0,538 \mathrm{~g} \mathrm{~cm}^{-3}$ para as posições longitudinais de $2 \%, 10 \%, 30 \%$, $50 \%$ e $75 \%$, respectivamente. 
Tabela 2. Resumo das análises de variância para densidade básica, estoque de carbono na madeira e densidade energética.

\begin{tabular}{ccccc}
\hline \multirow{2}{*}{ Fonte de Variação } & Graus de Liberdade & \multicolumn{3}{c}{ Quadrado Médio } \\
\cline { 5 - 5 } & & DB & ECM & DE \\
Clone & 38 & $0,01497^{*}$ & $3.672,2^{*}$ & $304,025^{*}$ \\
Erro na parcela & 78 & 0,00070 & 349,8 & 18,443 \\
Posição & 4 & $0,01571^{*}$ & $3.617,9 *$ & $287,988^{*}$ \\
Clone x Posição & 152 & $0,00080^{*}$ & $185,9 *$ & $14,690^{*}$ \\
Erro na subparcela & 312 & 0,00061 & 141,9 & 11,274 \\
CVe (\%) na parcela & - & 5,03 & 7,38 & 6,03 \\
CVe (\%) na subparcela & - & 4,69 & 4,70 & 4,71 \\
\hline
\end{tabular}

Em que: $\mathrm{CVe}(\%)$ = coeficiente de variação experimental; $\mathrm{DB}=$ densidade básica $\left(\mathrm{g} \mathrm{cm}^{-3}\right)$; $\mathrm{ECM}=$ estoque de carbono na madeira $\left(\mathrm{kg} \mathrm{m}^{-3}\right)$; $\mathrm{DE}=$ densidade energética $\left(\mathrm{Mcal} \mathrm{m}^{-3}\right)$. * = significativo ao nível de 5\% de significância pelo Teste $\mathrm{F}$.
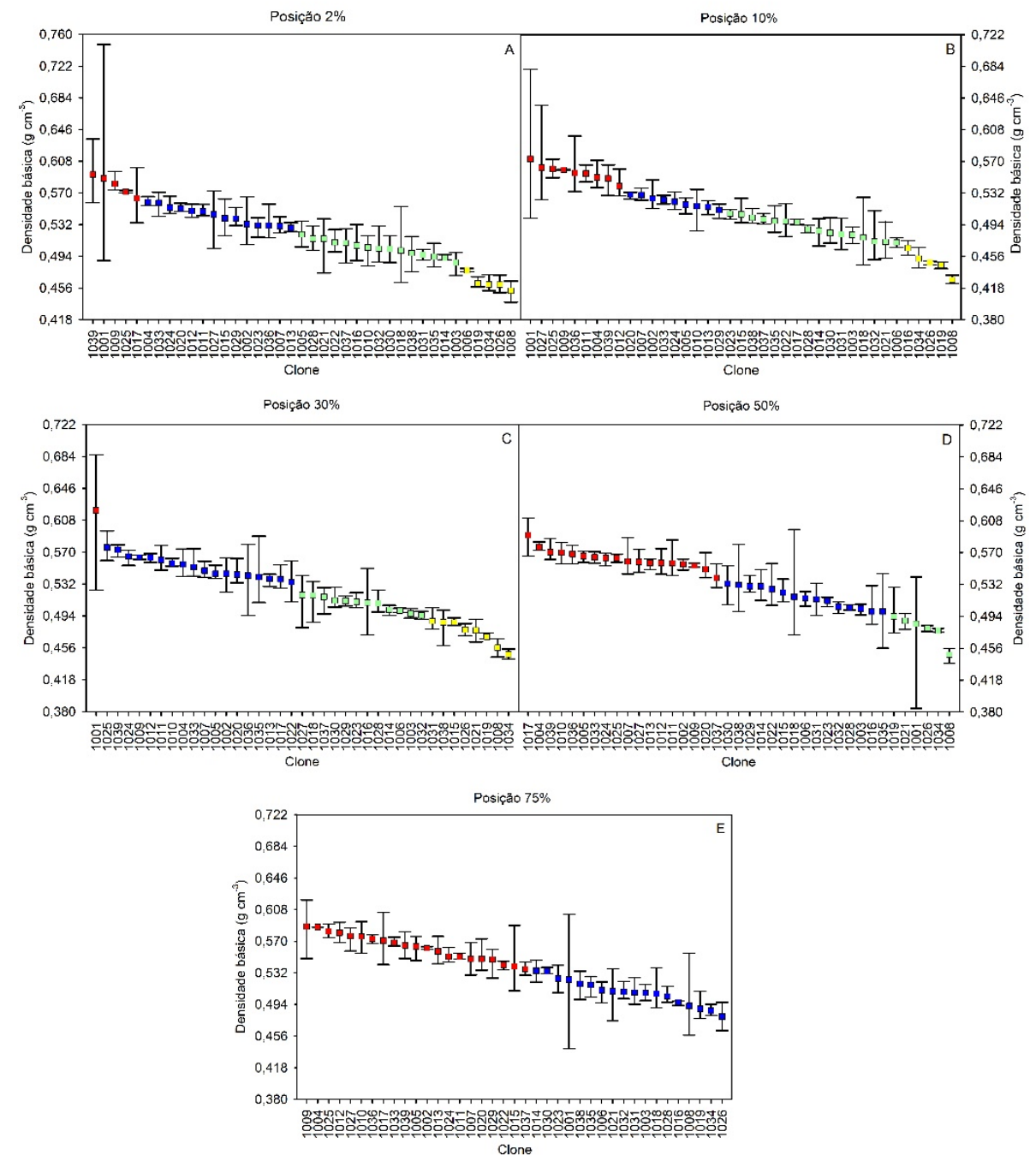

Figura 3. Densidade básica das posições longitudinais da madeira de trinta e nove clones de Eucalyptus sp. avaliados no município de Curvelo, Minas Gerais, Brasil. 
Intervalos de variação de densidade básica em clones de Eucalyptus semelhantes aos encontrados no presente estudo foram verificados por Sharma et al. (2015) na posição $2 \%$ $\left(0,440 \mathrm{~g} \mathrm{~cm}^{-3}-0,571 \mathrm{~g} \mathrm{~cm}^{-3}\right)$ e $10 \%\left(0,442 \mathrm{~g} \mathrm{~cm}^{-3}-0,552 \mathrm{~g} \mathrm{~cm}^{-3}\right)$, Hsing et al. (2016) na posição $25 \%\left(0,418 \mathrm{~g} \mathrm{~cm}^{-3}-0,467 \mathrm{~g} \mathrm{~cm}^{-3}\right)$ e $50 \%\left(0,410 \mathrm{~g} \mathrm{~cm}^{-3}-0,469 \mathrm{~g} \mathrm{~cm}^{-3}\right)$ e por Sturion et al. (1987) na posição $75 \%\left(0,502 \mathrm{~g} \mathrm{~cm}^{-3}\right.$ a $\left.0,706 \mathrm{~g} \mathrm{~cm}^{-3}\right)$.

Os clones 1039, 1009, 1001, 1004 e 1025 se destacaram desde as posições mais inferiores do fuste com os maiores valores de densidade básica da madeira, o que os tornam promissores para usos que requerem boa resistência mecânica e para a produção de bioenergia. Elevada densidade básica, aliado a maior homogeneidade das propriedades do lenho, refletirá na produção de carvão vegetal com maiores densidades relativa aparente e energética e maior resistência mecânica (Costa et al., 2018; Figueiredo et al., 2018).

Na produção de carvão vegetal, o ideal é utilizar madeira com densidade básica acima de $0,500 \mathrm{~g} \mathrm{~cm}^{-3}$ (Santos et al., 2011). Conforme a classificação do IAWA (Wheeler et al., 1989), valores de densidade básica inferior a $0,500 \mathrm{~g} \mathrm{~cm}^{-3}$ configuram madeira de baixa densidade. Assim, os clones 1019, 1034, 1026 e 1008, apresentaram densidade básica nas diferentes posições longitudinais inferior a $0,500 \mathrm{~g} \mathrm{~cm}^{-3}$, o que os restringem para o uso bioenergético. No entanto, estes materiais podem ser indicados para outros usos, desde que melhor caracterizados.

Os materiais genéticos cuja densidade básica foi influenciada pela interação clone $x$ posição longitudinal estão representados na Figura 4. Dos 39 clones avaliados, apenas 6 (15\%) apresentaram efeito significativo da variação longitudinal da densidade básica.

Foram utilizados modelos de regressão polinomial do tipo cúbico para os clones 1001 (Eucalyptus urophylla) e 1017 (Eucalyptus urophylla); linear para os clones 1005 (Eucalyptus urophylla), 1008 (Eucalyptus urophylla) e 1010 (Eucalyptus urophylla); e polinomial quadrático para o clone 1015 (Eucalyptus urophylla), para expressar o comportamento da densidade básica no sentido base-topo dos fustes.

Os padrões de variação da densidade básica dos clones 1001 (i), 1005 (ii), 1008 (ii), 1010 (ii), 1015 (iii) e 1017 (iv) foram: (i) crescente até 30\% do fuste, decrescendo até a posição 50\%, tornando a crescer até as posições superiores; (ii) crescente no sentido base-topo; (iii) poucas variações da densidade básica no fuste, mostrando-se mais homogêneo; e (iv) decréscimo na densidade básica até a posição 10\% e acréscimo até a posição $50 \%$.

Os dois primeiros padrões que mostram elevada densidade básica nas regiões basal e apical do fuste de Eucalyptus estão provavelmente relacionados às exigências mecânicas de sustentação do tronco e da copa das árvores, principalmente em resposta a ação dos ventos (Sette Junior et al., 2012). Como consequência, ocorrem modificações estruturais no xilema secundário visando à formação de lenho de reação (Monteiro et al., 2010), tal como a redução na produção de elementos vasculares e diâmetro desses elementos (Beaudoin et al., 1992; Vale et al., 1999).

O terceiro padrão é o mais requerido visando à produção de carvão vegetal, devido maior homogeneidade da densidade básica do fuste. O clone representante desse padrão (1015 - $E$. urophylla) apresentou produtividade energética média (Protásio et al., 2019), o que ratifica sua recomendação para o setor energético. A redução da densidade no sentido base-topo visualizada no quarto padrão está relacionada provavelmente a diminuição da porcentagem de lenho adulto e, consequentemente, da maior proporção de madeira juvenil, de menor densidade (Hsing et al., 2016).

Protásio et al. (2017) e Protásio et al. (2019) avaliaram os mesmos materiais genéticos do presente estudo, verificaram que os maiores valores de densidade básica não foram reportados para os materiais genéticos com maiores valores de volume individual, consequentemente, menores valores para altura e diâmetro. Assim, sugere-se que os clones de maiores densidades concentraram suas energias na formação de lenho de reação em resposta às condições ambientais (Vidaurre et al., 2013), em detrimento de privilegiar o crescimento e produção de biomassa. 


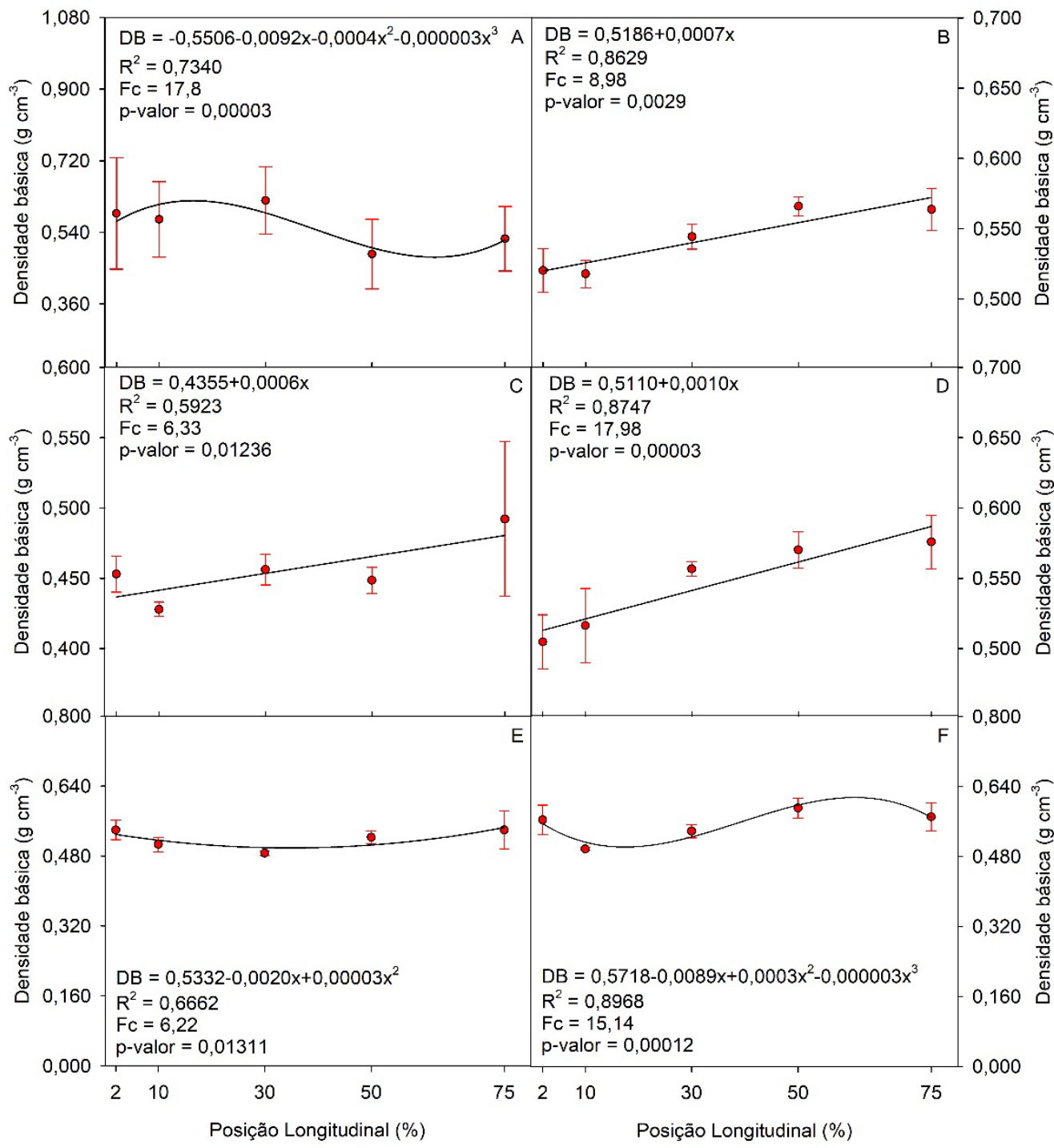

Figura 4. Variação da densidade básica da madeira no sentido longitudinal do fuste dos clones 1001 (A), 1005 (B), 1008 (C), 1010 (D), 1015 (E) e 1017 (F) de um reflorestamento no município de Curvelo, Minas Gerais, Brasil.

Alzate et al. (2005), estudaram a variação longitudinal (0\%, 10\%, 30\%, 50\% e 75\% da altura) da densidade básica da madeira em clones de Eucalyptus, e reportaram 3 padrões de variação: (i) decrescente da base até a posição 50\%, aumentando nas regiões superiores do fuste de Eucalyptus grandis; (ii) leve aumento da densidade básica da madeira do híbrido $E$. grandis x E. urophylla no sentido base-topo; e (iii) redução da densidade básica ao longo do fuste de Eucalyptus saligna. Portanto, a pesquisa realizada demonstra que o padrão de variação da densidade básica no sentido longitudinal do fuste deve ser considerado no processo de classificação de materiais, principalmente para a produção de carvão vegetal siderúrgico. Nesse sentido, buscam-se clones que apresentem baixa variação da densidade básica da base para o topo das árvores, conforme o segundo padrão identificado por Alzate et al. (2005) e detectado nesta pesquisa para o clone 1015 de $E$. urophylla.

A variabilidade longitudinal do estoque de carbono do fuste dos clones de Eucalyptus decresceu da base até a posição de $10 \%$, aumentando no sentido do topo do fuste (Figura 5). Os valores médios apresentados foram de $252,1 \mathrm{~kg} \mathrm{~m}^{-3}, 244,9 \mathrm{~kg} \mathrm{~m}^{-3}, 253,2 \mathrm{~kg} \mathrm{~m}^{-3}, 256,9 \mathrm{~kg} \mathrm{~m}^{-}$ ${ }^{3}$ e $259,6 \mathrm{~kg} \mathrm{~m}^{-3}$ para as posições de $2 \%, 10 \%, 30 \%, 50 \%$ e $75 \%$, respetivamente (Figura 5). 
Analisando cada posição longitudinal, as variações foram de $216 \mathrm{~kg} \mathrm{~m}^{-3}$ a $287,7 \mathrm{~kg} \mathrm{~m}^{-3}$ (posição de 2\%) (Figura 5A), $204 \mathrm{~kg} \mathrm{~m}^{-3}$ a 278,3 $\mathrm{kg} \mathrm{m}^{-3}$ (posição de 10\%) (Figura 5B), 215,3 $\mathrm{kg} \mathrm{m}^{-3}$ a $300,7 \mathrm{~kg} \mathrm{~m}^{-3}$ (posição de 30\%) (Figura 5C), 213,9 $\mathrm{kg} \mathrm{m}^{-3}$ a $284,1 \mathrm{~kg} \mathrm{~m}^{-3}$ (posição de $50 \%$ ) (Figura 5D) e de $231,8 \mathrm{~kg} \mathrm{~m}^{-3}$ a $285,1 \mathrm{~kg} \mathrm{~m}^{-3}$ (posição de $75 \%$ ) (Figura 5E). As posições $30 \%$ (85,4 $\left.\mathrm{kg} \mathrm{m}^{-3}\right)$ e $75 \%\left(53,3 \mathrm{~kg} \mathrm{~m}^{-3}\right)$ apresentaram as maiores e menores variações de estoque de carbono, respectivamente. Quanto à variação dentro dos materiais genéticos estudados, destacam-se os clones 1001, 1009, 1025 e 1039, por apresentarem os maiores valores de carbono por volume ao longo do fuste. Os clones 1009, 1025 e 1039 estão reunidos nos primeiros grupos formados pelo teste Scott-Knott da base até o topo do fuste, enquanto que o clone 1001 aparece entre os materiais genéticos de maiores valores da base até a posição de $30 \%$.
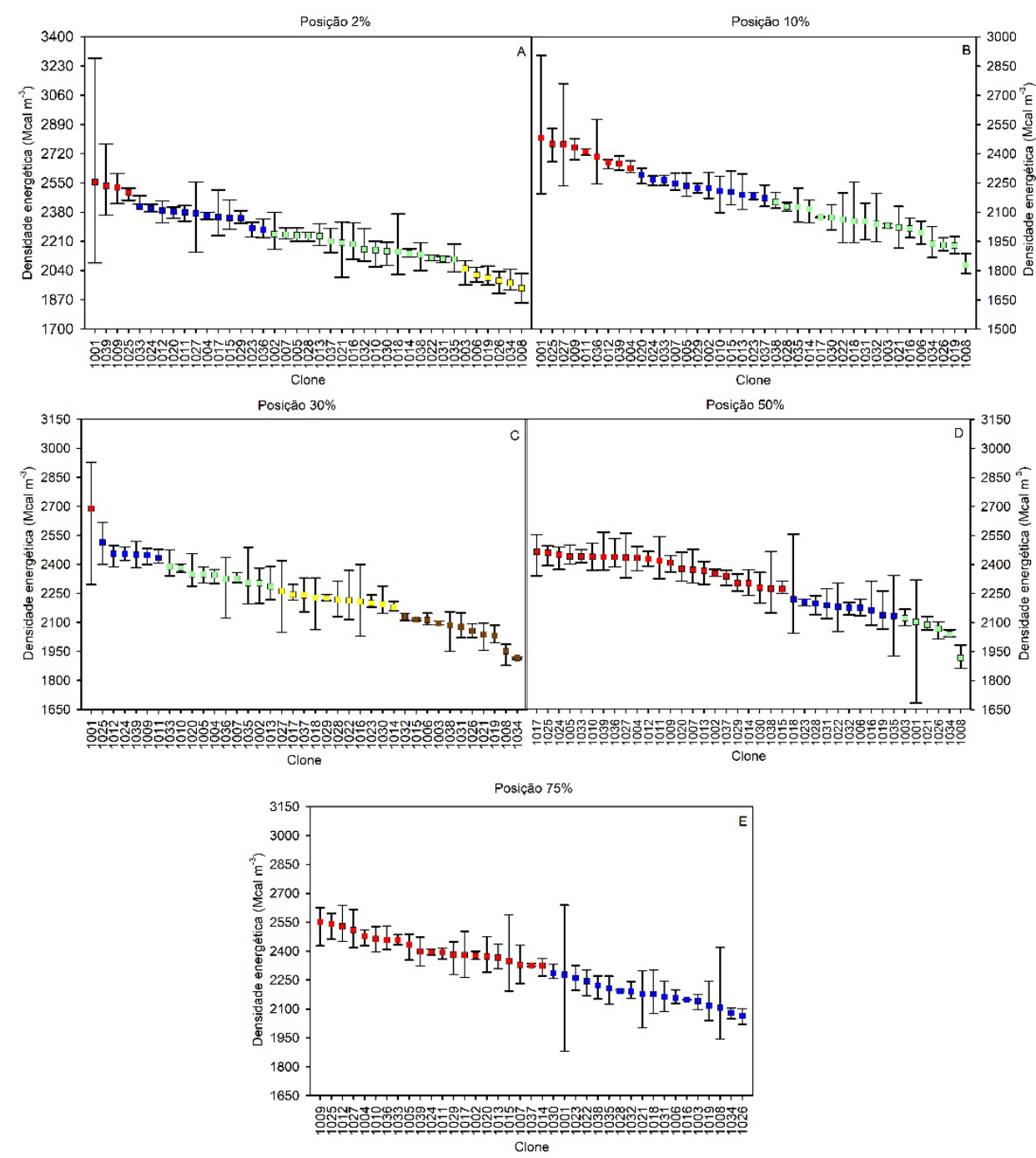

Figura 5. Estoque de carbono das posições longitudinais da madeira de trinta e nove clones de Eucalyptus sp. de um reflorestamento no município de Curvelo, Minas Gerais, Brasil.

O comportamento do estoque de carbono no sentido longitudinal do fuste do clone 1001 (Eucalyptus urophylla) foi explicado por um modelo de regressão do tipo polinomial cúbico (Figura 6A). O modelo do tipo polinomial linear foi adotado para os clones 1005, 1008 e 1010 (Figura 6B, 6C e 6D), e o modelo polinomial quadrático para os clones 1015 (Eucalyptus urophylla) e 1017 (Eucalyptus urophylla) (Figura 6E e 6F). Materiais genéticos com elevado estoque de carbono possuem alta afinidade ao uso bioenergético, visto que esta variável é representada 
pela combinação de duas importantes características desejáveis (densidade básica e teor de carbono elementar) em programas de melhoramento genético (Protásio et al., 2014; Weber et al., 2017). Além disso, madeiras de média a alta densidade básica, associadas ao alto estoque de carbono, são preferíveis no setor siderúrgico por produzirem biorredutores de maior densidade energética e volume de carbono fixo, alta resistência à abrasão e maior rendimento gravimétrico (Pereira et al., 2013; Protásio et al., 2015).

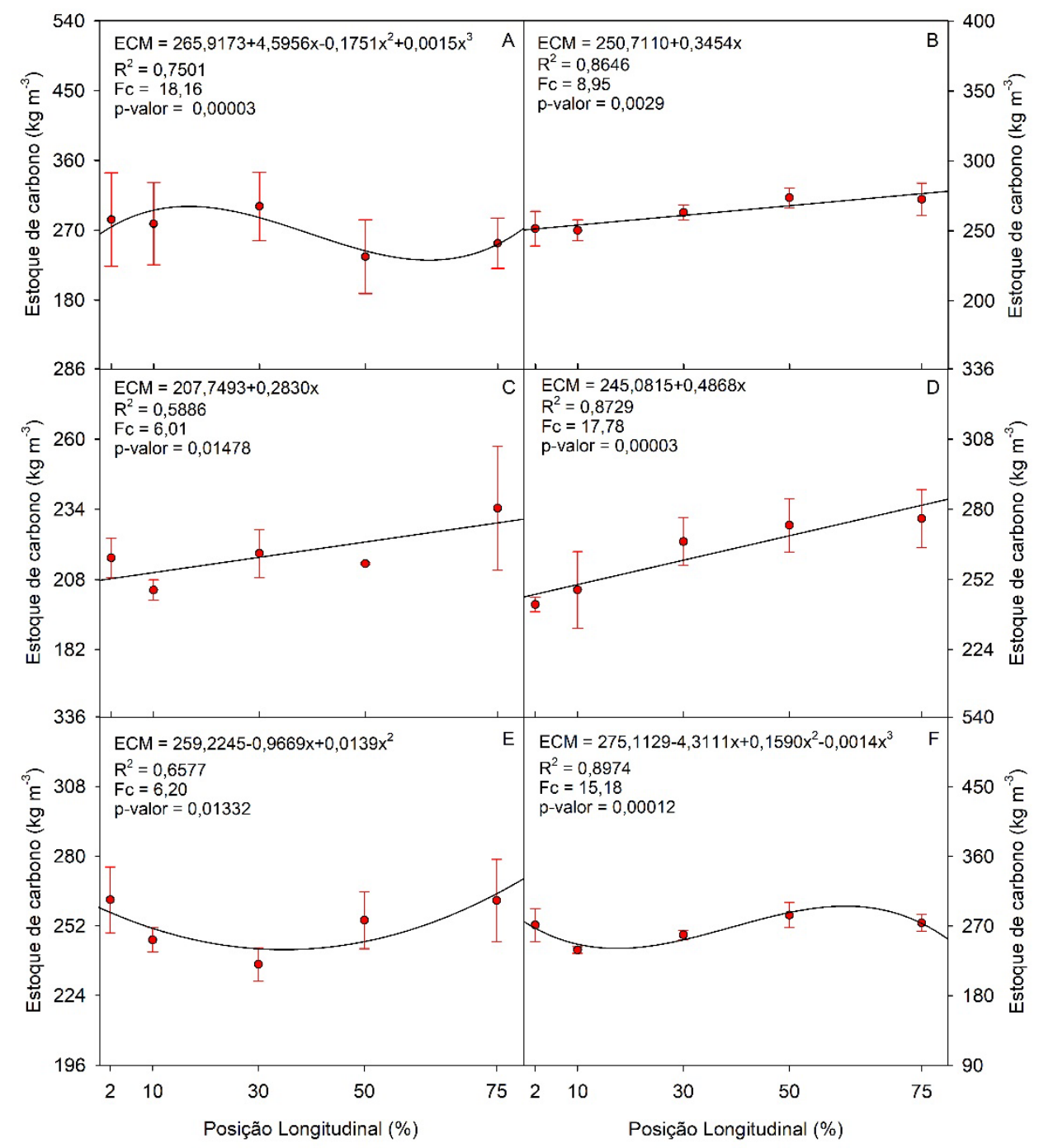

Figura 6. Variação do estoque de carbono da madeira no sentido longitudinal do fuste dos clones 1001 (A), 1005 (B), 1008 (C), 1010 (D), 1015 (E) e 1017 (F) de um reflorestamento no município de Curvelo, Minas Gerais, Brasil.

A densidade energética da madeira ao longo das posições longitudinais do fuste decresceu da base até a posição de 10\%, aumentando no sentido do topo do fuste (Figura 7). Os valores médios para as posições de $2 \%, 10 \%, 30 \%, 50 \%$ e $75 \%$ foram de $2332,7 \mathrm{Mcal} \mathrm{m}^{-3}$, $2258,8 \mathrm{Mcal} \mathrm{m}^{-3}, 2323,1 \mathrm{Mcal} \mathrm{m}^{-3}, 2367,3 \mathrm{Mcal} \mathrm{m}^{-3}$ e 2387,3 Mcal m${ }^{-3}$, respectivamente (Figura 7). A representação do comportamento da densidade energética seguiu o mesmo padrão observado para a densidade básica da madeira (Figura 8).

Destacam-se, novamente, os clones 1001, 1009, 1025 e 1039 com os melhores resultados de densidade energética. A variação ao longo do fuste para estes materiais genéticos segue a 
mesma tendência observada para o estoque de carbono, destacando-se por apresentar maior densidade básica da madeira (Figura 3). Houve correlação linear entre densidade básica da madeira e densidade energética $(r=0,9798)$ (Figura 9), mostrando haver forte influência da primeira variável sobre a segunda. A densidade energética é um importante parâmetro para combustíveis sólidos por representar a quantidade de energia armazenada em determinado volume (Jesus et al., 2017; Simetti et al., 2018). Dessa forma, programas de melhoramento genético de clones de Eucalyptus visando ganhos no estoque de carbono e densidade energética podem ser conduzidos a partir da avaliação da densidade básica da madeira.
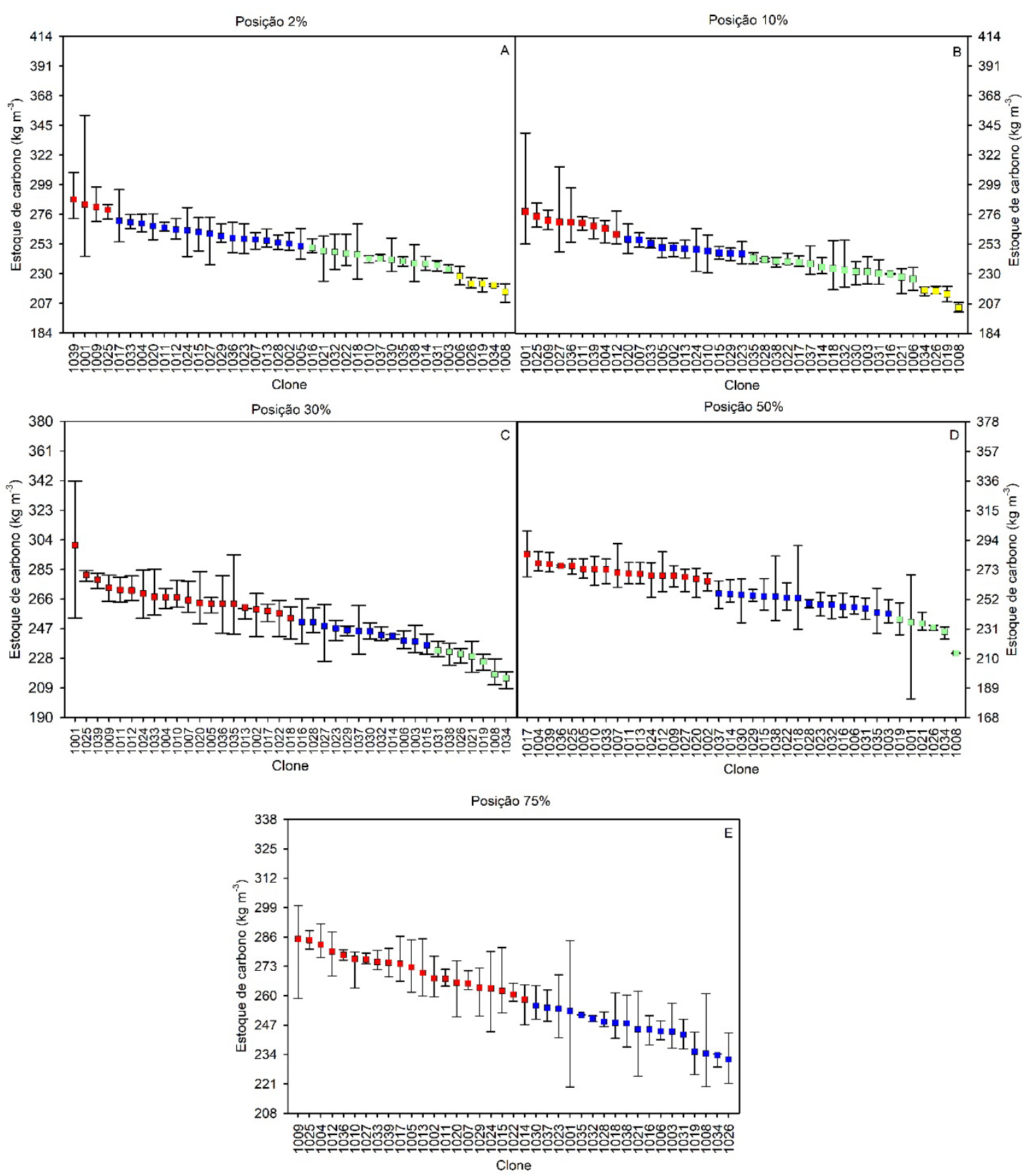

Figura 7. Densidade energética das posições longitudinais da madeira de trinta e nove clones de Eucalyptus sp. de um reflorestamento no município de Curvelo, Minas Gerais, Brasil.

Em geral, os clones 1001, 1009, 1025 e 1039 apresentaram maiores valores de densidade básica da madeira (ver Figura 3), confirmando a forte correlação linear entre 
esta propriedade física e os estoques de carbono e a densidade energética (Figura 9). Nas posições de $2 \%, 10 \%$ e $30 \%$, os clones 1025 e 1039 integraram o grupo com os maiores valores de densidade básica, densidade energética e estoque de carbono, ocorrendo o mesmo para os clones 1009 e 1039 nas posições de 50\% e 75\%. A partir dos resultados encontrados pode-se afirmar que os clones 1009, 1025 e 1039 apresentam considerável potencial para fornecimento de matéria-prima para processos de conversão termoquímica, como carbonização e combustão. Futuros estudos deverão ser conduzidos visando compreender detalhadamente as variações da composição química das madeiras dos clones estudados.

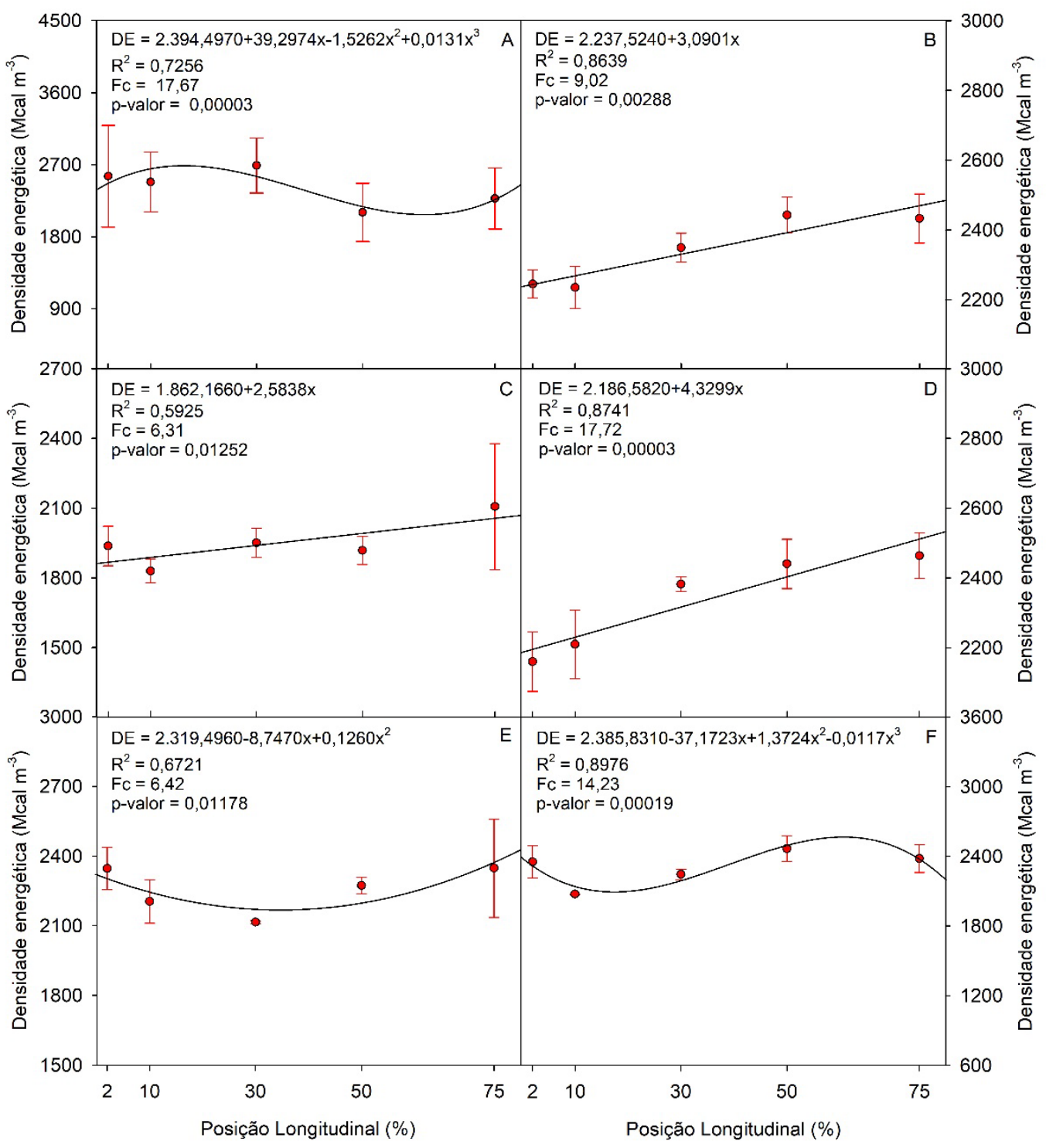

Figura 8. Variação da densidade energética da madeira no sentido longitudinal do fuste dos clones 1001 (A), 1005 (B), 1008 (C), 1010 (D), 1015 (E) e 1017 (F) de um reflorestamento no município de Curvelo, Minas Gerais, Brasil. 

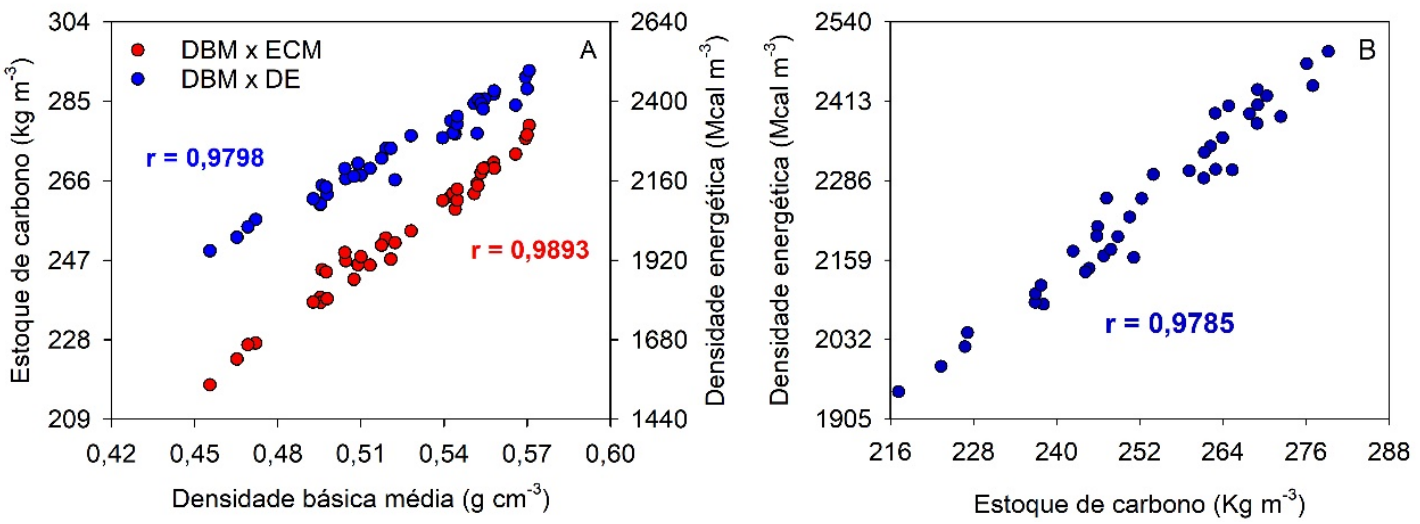

Figura 9. Correlação linear de Pearson da densidade básica da madeira (DBM) com o estoque de carbono (ECM) e densidade energética (DE) (A) e do estoque de carbono com a densidade energética (B) de trinta e nove clones de Eucalyptus de um reflorestamento no município de Curvelo, Minas Gerais, Brasil.

\section{CONCLUSÃO}

O padrão de variação da densidade básica no sentido longitudinal do fuste deve ser considerado no processo de classificação de clones de Eucalyptus para a produção de carvão vegetal siderúrgico.

A densidade básica da madeira apresenta padrões de média e baixa variabilidade entre os materiais genéticos e posições longitudinais do fuste, respectivamente. Observou-se tendência dos clones de madeiras mais densas apresentarem menor variação longitudinal das densidades básica e energética e estoque de carbono por volume.

Quatro padrões de variação da densidade básica do fuste foram observados para alguns clones de Eucalyptus urophylla e de Eucalyptus sp. Para clones provenientes de híbridos de $E$. urophylla, E. camaldulensis, E. grandis e E. pellita não foram encontradas variações consideráveis na densidade básica, densidade energética e no estoque de carbono no sentido longitudinal do fuste.

\section{AGRADECIMENTOS}

Os autores expressam seus sinceros agradecimentos a CAPES (código de financiamento 001) e ao CNPq (processos $n^{\circ} 141439 / 2014-9$ e $n^{\circ} 306793 / 2019-9$ ) pela concessão de bolsas de estudo aos pesquisadores, a FAPEMIG (processo PPM-00210-18) pelo financiamento da pesquisa e à empresa Plantar pela doação das madeiras, condução dos plantios experimentais e auxílio financeiro.

\section{REFERÊNCIAS}

Alzate, S. B. A., Tomazello Filho, M., \& Piedade, S. M. S. (2005). Variação longitudinal da densidade básica da madeira de Eucalyptus grandis Hill ex Maiden, E. saligna Sm. e E. grandis x urophylla. Scientia Forestalis, 68, 87-95.

Associação Brasileira de Normas Técnicas - ABNT. (1984). NBR 8633: Carvão vegetal - Determinação do poder calorífico - Método de ensaio. Rio de Janeiro: ABNT.

Associação Brasileira de Normas Técnicas - ABNT. (2003). NBR 11941: Madeira - Determinação da densidade básica. Rio de Janeiro: ABNT.

Barotto, A. J., Monteoliva, S., Gyenge, J., Martínez-Meier, A., \& Fernández, M. E. (2018). Functional relationships between wood structure and vulnerability to xylem cavitation in races of Eucalyptus globulus differing in wood density. Tree Physiology, 38(2), 243-251. PMid:29177476.

http://dx.doi.org/10.1093/treephys/tpx138. 
Barotto, A. J., Monteoliva, S., Gyenge, J., Martínez-Meier, A., Moreno, K., Tesón, N., \& Fernández, M. E. (2017). Wood density and anatomy of three Eucalyptus species: implications for hydraulic conductivity. Forest Systems, 26(1), 1-11. http://dx.doi.org/10.5424/fs/2017261-10446.

Batista, D. C., Klitzke, R. J., \& Santos, C. V. T. (2010). Densidade básica e retratibilidade da madeira de clones de três espécies de Eucalyptus. Ciência Florestal, 20(4), 665-674. http://dx.doi.org/10.5902/198050982425.

Beaudoin, M., Hernández, R. E., Koubaa, A., \& Poliquin, J. (1992). Interclonal, intraclonal and within-tree variation in wood density of poplar hybrid clones. Wood and Fiber Science, 24(2), 147-153.

Carneiro, A. C. O., Castro, A. F. N. M., Castro, R. V. O., Santos, R. C., Ferreira, L. P., Damásio, R. A. P., \& Vital, B. R. (2014). Potencial energético da madeira de Eucalyptus sp. em função da idade e de diferentes materiais genéticos. Revista Árvore, 38(2), 375-381. http://dx.doi.org/10.1590/S010067622014000200019.

Climate-Data.Org (2017). Dados climáticos para cidades mundiais. Oedheim: AM Online Projects. Recuperado em 23 de outubro 2018, de https://pt.climate-data.org/america-do-sul/brasil/minasgerais/curvelo-24917/

Costa, L. J., Lima, L. V. L., Paula, M. O., Carneiro, A. C. O., Reis, M. F. C., \& Soares, J. D. (2018). Correlation between compression strength parallel of wood and charcoal of Eucalyptus clones. Scientia Forestalis, 46(120), http://dx.doi.org/10.18671/scifor.v46n120.09.

Couto, A. M., Protásio, T. P., Reis, A. A., \& Trugilho, P. F. (2012). Amostragens longitudinais alternativas para a determinação da densidade básica em clones de Eucalyptus sp. Floresta e Ambiente, 19(2), 184-193. http://dx.doi.org/10.4322/floram.2012.022.

Dias, A. C. C., Marchesan, R., Almeida, V. C., Monteiro, T. C., \& Moraes, C. B. (2018). Relação entre a densidade básica e as retrações em madeira de teca. Ciência da Madeira, 9(1), 37-44. http://dx.doi.org/10.12953/2177-6830/rcm.v9n1p37-44.

Downes, G. M., Hudson, I. L., Raymond, C. A., Dean, G. H., Michell, A. J., \& Schimleck, R. (1997). Sampling plantation eucalypts for wood and fiber properties. Hobart: CSIRO. http://dx.doi.org/10.1071/9780643105287.

Ferreira, E. B., Cavalcanti, P. P., \& Nogueira, D. A. (2018). ExpDes: experimental designs. $R$ package version 1.2.0. Recuperado em 8 de novembro de 2018, de https://CRAN.R-project.org/package=ExpDes

Figueiredo, M. E. O., Longue Júnior, D., Pereira, A. K. S., Carneiro, A. D. C. O., \& Silva, C. M. S. (2018). Potencial da madeira de Pterogyne nitens Tul. (madeira-nova) para produção de carvão vegetal. Ciência Florestal, 28(1), 420-431. http://dx.doi.org/10.5902/1980509831620.

Fox, J., \& Weisberg, S. (2011). An \{R\} companion to applied regression (2nd ed.). Thousand Oaks CA: Sage. Recuperado em 8 de novembro de 2018, de http://socserv.socsci.mcmaster.ca/jfox/Books/Companion

Gatto, A., Barros, N. F., Novais, R. F., Silva, I. R., Leite, H. G., \& Villani, E. M. A. (2011). Estoque de carbono na biomassa de plantações de eucalipto na região centro-leste do estado de Minas Gerais. Revista Árvore, 35(4), 895-905. http://dx.doi.org/10.1590/S0100-67622011000500015.

Hsing, T. Y., Paula, N. F., \& Paula, R. C. (2016). Características dendrométricas, químicas e densidade básica da madeira de híbridos de Eucalyptus grandis x Eucalyptus urophylla. Ciência Florestal, 26(1), 273-283. http://dx.doi.org/10.5902/1980509821119.

Jesus, M. S., Costa, L. J., Ferreira, J. C., Freitas, F. P., Santos, L. C., \& Rocha, M. F. V. (2017). Caracterização energética de diferentes espécies de Eucalyptus. Floresta, 47(1), 11-16. http://dx.doi.org/10.5380/rf.v47i1.48418.

Leite, E. R. S., Protásio, T. P., Rosado, S. C. S., Trugilho, P. F., Valle, M. L. A., \& Siqueira, H. F. (2015). Composição química elementar da madeira e do carvão vegetal de Coffea arábica para uso bioenergético. Coffee Science, 10(4), 537-547.

Litton, C., Raich, J. W., \& Ryan, M. G. (2007). Carbon allocation in forest ecosystems. Global Change Biology, 13(10), 2089-2109. http://dx.doi.org/10.1111/j.1365-2486.2007.01420.x.

Luna, R. K., Thakur, N. S., Gunaga, R. P., \& Kumar, V. (2016). Biomass, carbon stock and carbon dioxide removal across different girth classes of Eucalyptus species in Punjab: implication for Eucalyptus plantations. Journal of Tree Sciences, 35(1), 13-20.

Monteiro, T. C., Vieira, R. S., Lima, J. T., Baraúna, E. E. P., Carvalho, D. M., \& Lima, M. T. (2010). Influência do lenho de tração nas propriedades físicas da madeira de Eucalyptus sp. Journal of Biotechnology and Biodiversity, 1(1), 6-11. http://dx.doi.org/10.20873/jbb.uft.cemaf.v1n1.monteiro. 
Mori, C. L. S. O., Mori, F. A., Lima, J. T., Trugilho, P. F., \& Oliveira, A. C. (2004). Influência das características tecnológicas na cor da madeira de eucaliptos. Ciência Florestal, 14(2), 123-132. http://dx.doi.org/10.5902/198050981812.

Pereira, B. L. C., Carneiro, A. C. O., Carvalho, A. M. M., Colodette, J. L., Oliveira, A. C., \& Fontes, M. P. F. (2013). Influence of chemical composition of Eucalyptus wood on gravimetric yield and charcoal properties. BioResources, 8(3), 4574-4592. http://dx.doi.org/10.15376/biores.8.3.4574-4592.

Protásio, T. P., Couto, A. M., Reis, A. A., \& Trugilho, P. F. (2013). Seleção de clones de Eucalyptus para a produção de carvão vegetal e bioenergia por meio de técnicas univariadas e multivariadas. Scientia Forestalis, 41, 15-28.

Protásio, T. P., Couto, A. M., Trugilho, P. F., Guimarães Junior, J. B., Lima Junior, P. H., \& Silva, M. M. O. (2015). Avaliação tecnológica do carvão vegetal da madeira de clones jovens de Eucalyptus grandis e Eucalyptus urophylla. Scientia Forestalis, 43(108), 801-816. http://dx.doi.org/10.18671/scifor.v43n108.6.

Protásio, T. P., Goulart, S. L., Neves, T. A., Trugilho, P. F., Ramalho, F. M. G., \& Queiroz, L. M. R. S. B. (2014). Qualidade da madeira e do carvão vegetal oriundos de floresta plantada em Minas Gerais. Pesquisa Florestal Brasileira, 34(78), 111-123. http://dx.doi.org/10.4336/2014.pfb.34.78.657.

Protásio, T. P., Scatolino, M. V., Araújo, A. C. C., Oliveira, A. F. C., Figueiredo, I. C. R., Assis, M. R., \& Trugilho, P. F. (2019). Assessing proximate composition, Extractive concentration, and lignin quality to determine appropriate parameters for selection of superior Eucalyptus firewood. BioEnergy Research, 12(3), 626-641. http://dx.doi.org/10.1007/s12155-019-10004-x.

Protásio, T. P., Trugilho, P. F., Araujo, A. C. C., Bastos, T. A., Rosado, S. C. S., \& Pinto, J. F. N. (2017). Classificação de clones de Eucalyptus por meio da relação siringil/guaiacil e das características de crescimento para uso energético. Scientia Forestalis, 45(113), 327-341. http://dx.doi.org/10.18671/scifor.v45n114.09.

R Core Team. (2017). R: a language and environment for statistical computing. Vienna, Austria: R Foundation for Statistical Computing. Recuperado em 12 de agosto de 2017, de http://www.Rproject.org/

Rodrigues, É. A. C., Rosado, S. C. S., Trugilho, P. F., \& Santos, A. M. (2008). Seleção de clones de Eucalyptus para as propriedades físicas da madeira avaliadas em árvores no campo. Cerne, 14(2), 147-152.

Santos, L. C., Carvalho, A. M. M. L., Pereira, B. L. C., Oliveira, A. C., Carneiro, A. C. O., \& Trugilho, P. F. (2012). Propriedades da madeira e estimativas de massa, carbono e energia de clones de Eucalyptus plantados em diferentes locais. Revista Árvore, 36(5), 971-980. http://dx.doi.org/10.1590/S010067622012000500019.

Santos, R. C., Carneiro, A. C. O., Castro, A. F. M., Castro, R. V. O., Bianche, J. J., Souza, M. M., \& Cardoso, M. T. (2011). Correlações entre os parâmetros de qualidade da madeira e do carvão vegetal de clones de eucalipto. Scientia Forestalis, 39(90), 221-230.

Sette Junior, C. R., Oliveira, I. R., Tomazello Filho, M., Yamaji, F. M., \& Laclau, J. P. (2012). Efeito da idade e posição de amostragem na densidade e características anatômicas da madeira de Eucalyptus grandis. Revista Árvore, 36(6), 1183-1190. http://dx.doi.org/10.1590/S0100-67622012000600019.

Sharma, S. K., Shukla, S. R., Shashikala, S., \& Poornima, V. S. (2015). Axial variations in anatomical properties and basic density of Eucalyptus urograndis hybrid (Eucalyptus grandis $\times$ E. urophylla) clones. Journal of Forestry Research, 26(3), 739-744. http://dx.doi.org/10.1007/s11676-015-0080-6.

Silva, C. A., Klauberg, C., Carvalho, S. P. C., Piccolo, M. C., \& Rodriguez, L. C. E. (2015). Estoque de carbono na biomassa aérea florestal em plantações comerciais de Eucalyptus spp. Scientia Forestalis, 43(105), 135-146.

Simetti, R., Bonduelle, G. M., \& Silva, D. A. (2018). Wood quality of five Eucalyptus species planted in Rio Grande do Sul, Brazil for charcoal production. Journal of Tropical Forest Science, 30(2), 175-181. http://dx.doi.org/10.26525/jtfs2018.30.2.175181.

Sturion, J. A., Pereira, J. C. D., Albino, J. C., \& Morita, M. (1987). Variação da densidade básica da madeira de doze espécies de Eucalyptus plantadas em Uberaba, MG. Boletim de Pesquisa Florestal, 14, 28-38.

Trugilho, P. F., Arantes, M. D. C., Pádua, F. A., Almado, R. P., \& Baliza, A. E. R. (2010). Estimativa de carbono fixado na madeira de um clone híbrido de Eucalyptus urophylla e Eucalyptus grandis. Cerne, 16, 33-40.

Vale, A. T., Brasil, M. A. M., \& Martins, I. S. (1999). Variação axial da densidade básica da madeira de Acacia mangium Willd aos sete anos de idade. Ciência Florestal, 9(2), 85-92. http://dx.doi.org/10.5902/19805098386. 
Vidaurre, G., Lombardi, L. R., Nutto, L., Oliveira, J. T. S., \& Arantes, M. D. C. (2013). Propriedades da madeira de reação. Floresta e Ambiente, 20(1), 26-37. http://dx.doi.org/10.4322/floram.2012.041.

Weber, J. C., Sotelo Montes, C., Abasse, T., Sanquetta, C. R., Silva, D. A., Mayer, S., Muñiz, G. I. B., \& Garcia, R. A. (2017). Variation in growth, wood density and carbon concentration in five tree and shrub species in Niger. New Forests, 49(1), 35-51. http://dx.doi.org/10.1007/s11056-017-9603-7.

Wheeler, E. A., Baas, P., \& Gasson, P. E. (Eds.). (1989). International association of wood anatomists: list of microscopic features for hardwood identification. IAWA Bulletin, 10(3), 219-232.

Wink, C., Reinert, D. J., Muller, I., Reichert, J. M., \& Jacomet, L. (2013). A idade das plantações de Eucalyptus sp. influenciando os estoques de carbono. Ciência Florestal, 23(2), 333-343. http://dx.doi.org/10.5902/198050989279.

Zanuncio, A. J. V., Lima, J. T., Monteiro, T. C., Carvalho, A. G., \& Trugilho, P. F. (2013). Secagem de toras de Eucalyptus e Corymbia para uso energético. Scientia Forestalis, 41(99), 353-360.

Contribuição dos Autores: MDRL e UOBJ: Conceituação, Análise Formal, Visualização, Escrita - Primeira Redação; MRA e ICNAM: Investigação e Metodologia; ICRF: Obtenção de Financiamento e Recursos; PFT: Obtenção de Financiamento, Recursos, Metodologia, Supervisão, Administração do Projeto e Escrita - Revisão e Edição; TPP: Conceituação, Análise Formal, Visualização, Investigação, Metodologia, Supervisão e Escrita - Revisão e Edição. 